\title{
BIBLIOMETRICS ANALYSIS ON “ROLE OF LIBRARY (A IN SUPPORTING KNOWLEDGE MANAGEMENT" PUBLISHED DURING 1999-2020
}

\author{
Tupan* \& Retno Asihanti Setiorini*
}

*Pusat Data dan Dokumentasi Ilmiah - Lembaga Ilmu Pengetahuan Indonesia Email: tupan712190@yahoo.com,r3tno.as@gmail.com

(Submitted: 10-06-2020, Revised: 17-12-2020, Accepted: 22-12-2020)

DOI: $10.2425 /$ kah.v8i2a10

\begin{abstract}
ABSTRAK: Perpustakaan harus berperan dalam mengelola pengetahuan yang dihasilkan oleh seluruh sivitas akademika agar dapat dimanfaatkan oleh siapa saja. Penelitian ini menganalisis publikasi tentang peran perpustakaan dalam mendukung manajemen pengetahuan. Data penelitian diperoleh dari database Scopus. Teknik pengambilan dengan dengan memasukkan kata kunci "Knowledge Management" and "Library" dengan batasan tahun terbit antara 1992-2020. Data yang diperoleh kemudian dikelompokkan berdasarkan tahun terbit, sumber publikasi dan jenis lieteratur. Untuk pemetaan kata kunci, penelitian ini menggunakan VosViewer. Hasil analisis menunjukkan bahwa publikasi penelitian tentang peran perpustakaan dalam mendukung manajemen pengetahuan paling banyak dilakukan pada tahun 2013 dan tahun 2016. Library Management merupakan jurnal yang paling banyak menerbitkan literatur terkait objek penelitian ini, yakni sebanyak 11 dokumen dengan jumlah sitasi sebanyak 185. Jenis dokumen terbanyak adalah dalam bentuk artikel. Dari pemetaaan VosViewer menunjukan ada empat kluster. Topik penelitian yang paling banyak dilakukan adalah knowledge management system, knowledge management, library and information science, academic libraries, knowledge sharing, knowledge management model, librarian, research development management, information science, innovation, library services, dan university libraries.
\end{abstract}

Kata kunci: Manajemen pengetahuan; Peran perpustakaan; Bibliometrika

ABSTRACT: Libraries must play a role in knowledge management created by all academicians so that it can be used by anyone. This study analyzes publications about the role of libraries in supporting knowledge management. The data were obtained from the Scopus database. The retrieval technique is by entering the keywords "Knowledge Management" and "Library" with a publication year limitation between 1992-2020. The data obtained were then grouped based on the year of publication, publication source and type of literature. For keyword mapping, this study used VosViewer. The results of the analysis showed that research publications on the role of libraries in supporting knowledge management were mostly carried out in 2013 and 2016. Library Management is the journal that publishes the most literature related to this research object, there were 11 documents with a total of 185 citations, was in the form of articles. From the VosViewer mapping, it showed that there were four clusters. Research topics that were mostly carried out were knowledge management systems, knowledge management, libraries and information science, academic libraries, knowledge sharing, knowledge management models, librarians, research development management, information science, innovation, library services, and university libraries.

Keywords: Knowledge management; Library roles; Bibliometrics

\section{PENDAHULUAN}

Manajemen pengetahuan penting tidak hanya bermanfaat bagi manajemen perpustakaan tetapi juga bermanfaat bagi pengguna perpustakaan. Kelompok pustakawan yang berfungsi dengan 
baik dengan kompetensi dan keterampilan yang tepat secara alami akan memberikan layanan yang lebih baik bagi pengguna perpustakaan (Daland, 2016). Hal senada dikatakan oleh Anjas Pratama (2018) bahwa manajemen pengetahuan merupakan suatu strategi yang mengubah aset intelektual organisasi, baik informasi terekam maupun inovasi dari anggotanya ke dalam produktivitas yang lebih tinggi untuk peningkatan daya saing. Konsep manajemen penegetahuan ini meliputi pengelolaan sumber daya manusia, dan tekhnologi informasi, dalam rangka mencapai peningkatan kualitas. Suwarno (2016) dalam bidang perpustakaan kegiatan manajemen pengetahuan dilakukan adalah kegiatan pengadaan koleksi, organisasi koleksi, jaringan informasi dan berbagi sumber informasi, pemeliharaan koleksi dan pemasaran informasi.

Haryanto (2018) mengatakan bahwa konsep manjemen pengetahuan di perpustakaan adalah metode pengelolaan pengetahuan yang terdiri dari multi informasi yang menuntut perubahan dari manajemen konvensional menuju manajemen modern. Manajemen pengetahuan di perpustakaan meliputi manajemen pengetahuan tentang pengoperasian perpustakaan, pengetahuan terkait pemustaka, pengetahuan tentang koleksi perpustakaan dan pengetahuan tentang fasilitas dan teknologi perpustakaan yang digunakan. Perpustakaan pada tataran konvensional mempunyai fungsi untuk mengumpulkan, mengolah, menyimpan, menyebarkan, dan berbagi informasi untuk memberikan layanan kepada penggunanya. Pada tataran pengelolaan manajemen pengetahuan modern perpustakaan perlu memperbaiki layanan kepada pemustaka dengan menjadi organisasi yang berfungsi meningkatkan proses pengelolaan pengetahuan dan inovasi. Skills pustakawan perlu terus ditingkatkan melalui peningkatan keterampilan dan pengetahuan baru untuk mendukung perubahan tersebut. Disamaping itu sklills yang dimilki pustakawan dapat meningkatkan efisiensi operasional serta melakukan manajemen pengetahuan di perpustakaan agar dapat mendukung kinerja organisasi dalam memberikan layanan yang terbaik kepada penggunanya.

Wulandari dan Risa (2020) adanya manajemen pengetahuan di perpustakaan dapat mendorong pengumpulan dan diseminasi pengetahuan, mempromosikan hasil karya ilmiah serta melindungi kekayaan intelektual yang dihasilkan oleh lembaga induk. Penerapan manajemen pengetahuan di perpustakaan juga dapat melindungi agar pengetahuan tacit dan ekplisit yang disimpan dapat ditemukan kembali oleh individu maupun organisasi jika diperlukan. Manajemen pengetahuan merupakan repositori lembaga yang dimiliki perpustakaan untuk mendukung pengajaran, pembelajaran dan penelitian.

Berdasarkan uraian di atas penelitian ini akan menganalisis publikasi penelitian yang berkaitan dengan peran perpustakaan dalam mendukung manajemen pengetahuan yang mana data diperoleh dari databse Scopus. Analisis ini bertujuan untuk mengetahui; 1) pertumbuhan publikasi penelitian peran perpustakaan dalam mendukung manajamen pengetahuan berdasarkan tahun, 2) mengetahui pertumbuhan publikasi peran perpustakaan dalam mendukung manajemen pengetahuan berdasarkan sumber, 3) jenis literatur yang tersedia untuk peran perpustakaan dalam mendukung manajemen pengetahuan, dan 4) pemetaan dan tren topik penelitian peran perpustakaan dalam mendukung manajemen pengetahuan.

\section{KAJIAN TERDAHULU}

Penelitian peran perpustakaan dalam mendukung manajemen pengetahuan dilakukan oleh Pinfield, Cox, dan Smith, (2014) menyatakan bahwa manajemen pengetahuan menjadi tantangan utama bagi organisasi/lembaga penelitian. Sejumlah besar data digital yang ada sedang diproduksi dalam berbagai bentuk dengan kecepatan tinggi di perguruan tinggi. Dalam penelitiannya yang menganalisis tenang kontribusi perpustakaan akademik dalam mendukung manajemen pengetahuan dalam konteks kelembagaan yang lebih luas. Hasil penelitian tersebut menunjukkan bahwa perpustakaan memainkan peran penting dalam manajemen pengetahuan, hubungannya dengan pemangku kepentingan lain seperti layanan TI dan pendukung penelitian. Penekanan saat ini dalam program manajemen pengetahuan adalah pada pengembangan kebijakan dan pedoman, infrastruktur teknologi dan layanan dukungan. Penggerak untuk pengembangan manajemen pengetuhuan meliputi penyimpanan, keamanan, kualitas, 
kepatuhan, pelestarian, dan berbagi. Berbagai faktor, termasuk tata kelola, sumber daya, dan keterampilan, diidentifikasi sebagai faktor yang mempengaruhi perkembangan manajemen pengetahuan yang sedang berlangsung.

Rahayu (2016) juga melakukan kajian peranan perpustakaan dalam mendukung manajemen pengetahuan repositori Kementerian Kelautan dan Perikanan. Dalam penelitiannya dikatakan bahwa melalui penerapan manajemen pengetahuan di perpustakaan akan menyebabkan terjadinya proses komunikasi ilmiah yang dapat terus berkembang, karena inti dari manajemen pengetahuan adalah berbagi atau sharing pengetahuan. Perpustakaan mengambil peran sebagai pengumpul, pengolah, penyimpan dan penyebar pengetahuan yang telah dihasilkan oleh para peneliti, penyuluh dan pengambil kebijakan. Dalam kegiatan perpustakaan manajemen pengetahuan bukan merupakan hal baru karena aktivitas manajemen pengetahuan adalah aktivitas keseharian perpustakaan. Kegiatan pengorganisasian selalu diikuti dengan penyimpanan. Jika kegiatan dilakukan di tingkat organisasi, pengetahuan disimpan dalam penyimpanan pengetahuan (knowledge repository) misalnya: server, yang dapat diakses secara kolektif untuk pemanfaatan bersama. Adanya knowledge repository ini dan ketersediaan data di dalamnya merupakan prasyarat terjadinya pertukaran dan penggabungan pengetahuan yang memungkinkan terciptanya pengetahuan baru.

Kajian lainnya juga dilakuan Husna dan Nelisa (2019) tentang implementasi manajemen pengetahuan (knowledge management) di Perpustakaan STIKes Alifah Padang. Penelitian ini mewawancarai dan mengobservasi pemustaka di Perpustakaan STIKes Alifah Padang. Hasil penelitian menunjukkan bahwa implementasi manajemen pengetahuan dengan menerapkan teknologi informasi di Perpustakaan STIKes Alifah dengan menggunakan aplikasi SIMPUS dan bidang temu kembali informasi dengan memanfaatkan katalog online. Dengan itu, ada peran perpustakaan tersebut dalam usahanya mengelola pengetahuan. Serupa, Adelia (2020) melakukan kajian posisi manajemen pengetahuan dalam perpustakaan. Kajian menggunakan pendekatan deskriptif kualitatif dengan metode studi literatur. Hasil kajian menyimpulkan bahwa perpustakaan merupakan lembaga pengelola pengetahuan manusia. Praktik pengelolaan perpustakaan tidak sebatas mengelola buku di rak-rak. Lebih dari itu, perpustakaan diharapkan mampu mengelola pengetahuan yang dihasilkan oleh lembaga induknya.

\section{METODOLOGI PENELITIAN}

Penelitian dilakukan dengan menggunakan metode analisis publikasi yaitu penelitian yang dilakukan dengan mencari artikel yang terkait dengan peran perpustakan dalam mendukung manajemen pengetahuan. Penelitian diawali dengan melakukan penelusuran melalui database Scopus. Penelusuran literatur dilakukan pada Bulan Desember 2020 menggunakan referensi jurnal online yang terindeks pada database Scopus. Penelusuran dilakukan untuk mencari materi yang relevan dengan menggunakan frasa kunci: (Title (library) AND Title (knowledge AND management)). Dari total hasil penelusuran ada sekitar 199 dokumen yang dapat dijadikan data penelitian. Data penelitian dikelompokkan berdasarkan parameter yang sesuai dengan tujuan penelitian. Hasil pengelompokkan data kemudian dianalisis menggunakan MS Excel. Hasil analisis kemudian dituangkan pada hasil dan pembahasan. Sedangkan untuk pemetaan kata kunci digunakan sofware VosViewer.

\section{HASIL DAN PEMBAHASAN}

\section{Pertumbuhan Jumlah Publikasi Per Tahun}

Gambar 1 menunjukkan bahwa jumlah publikasi peran perpustakaan dalam mendukung manjemen pengetahuan mengalami kenaikan yang signifikan dari tahun 1992 hingga 2013. Namun antara tahun 2014 dan 2015 publikasi mengalami penurunan dan terjadi kenaikan kembali mulai tahun 2016. Hal tersebut sesuai dengan pendapat Van Nunen et al. (2018) bahwa jumlah publikasi peer-reviewed merupakan salah satu indikator untuk mengetahui perkembangan penelitian ilmiah suatu subyek. Semakin banyak jumlah publikasi dapat diinterpretasikan bahwa topik yang didalami dalam suatu subyek semakin banyak. Pendapat ini juga didukung oleh Alajmi dan Alhaji (2018) yang melakukan penelitian untuk mengetahui trend penelitian knowledge management (KM) dengan menggunakan analisis bibliometrik. Hasil 
Tupan \& Retno Asihanti Setiorini: Bibliometrics analysis on "role of library is supporting knowledge management" published during 1999-2020

penelitian menunjukkan bahwa pertumbuhan jumlah artikel Knowledge management (KM) terjadi antara 2002 dan 2016.

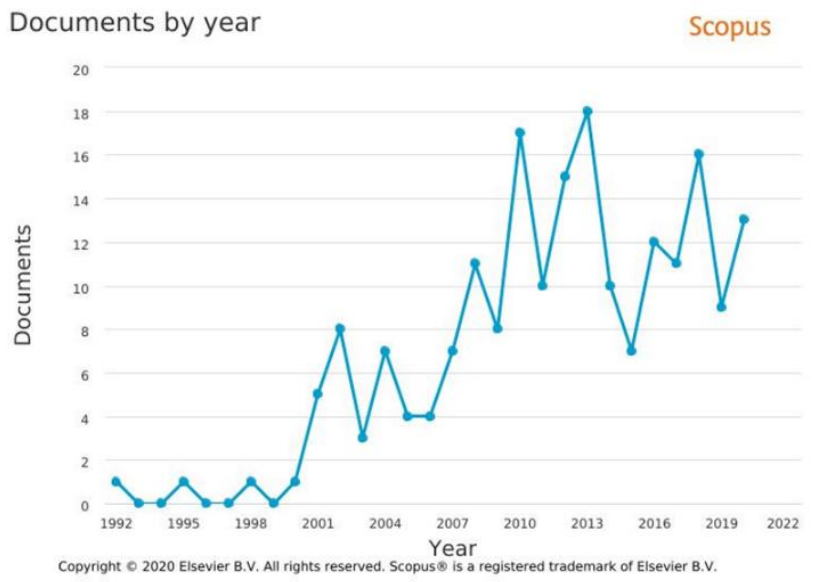

Gambar 1. Jumlah publikasi peran perpustakaan manjemen pengetahuan pertahun

\section{Besar Sumber Publikasi Peran Perpustakaan dalam Manajemen Pengetahuan}

Dari hasil penelusuran melalui database Scopus menunjukkan bahwa ada 10 besar sumber publikasi yang mempublikasikan penelitian tentang peran perpustakaan dalam mendukung manajemen pengetahuan. Library Management merupakan sumber publikasi yang paling banyak menerbitkan penelitian tentang peran perpustakaan dalam mendukung manajemen pengetahuan dengan jumlah dokumen sebanyak 11, kemudian disusul IFLA Journal 9 dokumen, Journal of Information and Knowledge Management 8 dokumen, Journal of Librarianship and Information Science dan Library Philosophy and Practice masing-masing 6 dokumen. Selengkapnya sumber publikasi yang memublikasikan penelitian tentang manajemen pengetahuan dapat dilihat pada Tabel 1 di bawah.

Berdasarkan jumlah sitasi menunjukkan bahwa Library Management merupakan sumber publikasi yang paling banyak disitir/disitasi yaitu sebanyak 185 sitasi, kemudian disusul Journal of Academic Librarianship sebanyak 146 sitasi, IFLA Journal sebanyak 54 sitasi, Journal of Information and Knowledge Management sebanyak 50 sitasi, Journal of Library Administration 40 sitasi dan International Information and Library Review sebanyak 29 sitasi.

Tabel 1. Sumber publikasi manajemen pengetahuan di perpustakaan

\begin{tabular}{lcc}
\hline \multicolumn{1}{c}{ Sumber Dokumen } & $\begin{array}{c}\text { Jumlah } \\
\text { dokumen }\end{array}$ & $\begin{array}{c}\text { Jumlah } \\
\text { sitasi }\end{array}$ \\
\hline Library Management & 11 & 185 \\
Ifla Journal & 9 & 54 \\
Journal of Information and Knowledge Management & 8 & 50 \\
Journal of Librarianship and Information Science & 6 & 5 \\
Library Philosophy and Practice & 6 & 7 \\
Advanced Materials Research & 4 & 0 \\
International Information and Library Review & 4 & 29 \\
Journal of Library Administration & 4 & 40 \\
Proceedings of The Association for Information Science and Technology & 4 & 5 \\
Journal of Academic Librarianship & 3 & 146 \\
\hline
\end{tabular}


Berdasarkan visualisasi network sumber publikasi peran perpustakaan dalam mendukung manajemen pengetahuan seperti terlihat pada Gambar 2 yang menunjukkan bahwa sepuluh besar sumber publikasi dibagi menjadi 3 kluster yaitu kluster 1 berwarna merah terdiri dari Journal of Information and Knowledge Management, Library Management, Library Philosophy and Practice, dan Proceedings of The Association for Information Science and Technology. Kluster 2 berwarna hijau terdiri dari International Information and Library Review, Journal of Academic Librarianship, dan Journal of Library Administration. Kluster 3 berwarna hijau muda terdiri dari IIFLA Journal dan Journal of Librarianship and Information Science.

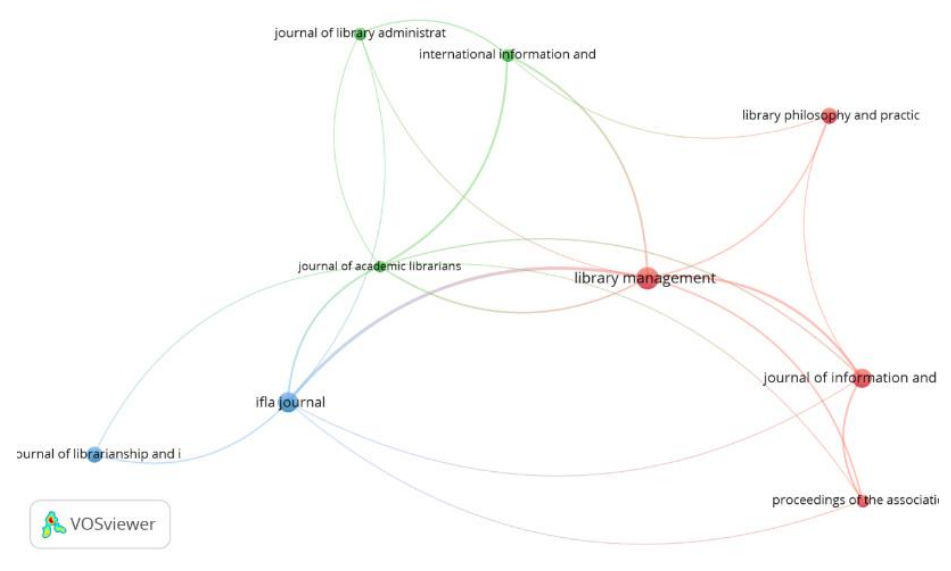

Gambar 2. Network visualisasi sumber publikasi manajemen pengetahuan

\section{Jenis Literatur yang Tersedia untuk Peran Perpustakaan dalam Manajemen Pengetahuan}

Berdasarkan Tabel 1. menunjukkan bahwa jenis literatur hasil penelusuran melalui database Scopus tentang peran perpustakaan dalam mendukung manajemen pengetahuan diperoleh 199 publikasi. Rincian jenis lieratur yang tersedia adalah artikel yang merupakan jenis literatur terbanyak yaitu sebanyak 120 publikasi, kemudian disusul conference papers sebanyak 51 publikasi, book chapters 12 publikasi, reviews 10 publikasi, books 4 publikasi dan editorial 2 publikasi.

Tabel 2. Jenis Literatur yang Tersedia untuk manajemen pengetahuan 1992-2020

\begin{tabular}{lc}
\hline \multicolumn{1}{c}{ Jenis Literatur } & Jumlah \\
\hline Article & 120 \\
Conference Paper & 51 \\
Book Chapter & 12 \\
Review & 10 \\
Book & 4 \\
Editorial & 2 \\
Jumlah & 199 \\
\hline
\end{tabular}

\section{Pemetaan dan Tren Topik Penelitian Peran Perpustakaan dalam Manajemen Pengetahuan}

Analisis pemetaan dan tren publikasi penelitian peran perpustakaan dalam mendukung manajemen pengetahuan dilakukan menggunakan visualisasi network, overlay, dan density dengan memanfaatkan VosViewer versi 1.6.14 untuk mengetahui peta jaringan yang ada di antara artikel-artikel dari metadata yang telah diunduh. Peta jaringan berdasarkan visualisasi network menunjukkan terbagi menjadi empat kluster seperti pada Gambar 3 berikut.

Kluster 1 berwarna merah terdiri dari innovation, knowledge, knowledge management strategy, librarian, librarians, medical libraries, library, management science, research 
development management, dan tacit knowledge. Kluster 2 berwarna hijau terdiri dari design/methodology, digital libraries, digital library, knowledge acquisition, knowledge base system, knowledge managemnt system, library services, word wide web. Kluster 3 berwarna biru terdiri explicit knowledge, information management, information service, information technology, knowledge management, libraries, library and information science. Kluster 4 berwarna kuning terdiri academic libraries, knowledge management, knowledge sharing, service innovation, structural equation modeling, university libraries. Kluster 5 berwarna ungu terdiri dari information science, knowledge management model, knowledge management tool, library management, dan management. Hal tersebut sesuai dengan pendapat Koç et.al. (2019) melakukan analisis kata kunci yang berhubungan dengan knowledge management menunjukkan bahwa kata kunci yang sering muncul adalah knowledge management menduduki ranking pertama, diikuti oleh knowledge sharing, knowledge transfer dan knowledge creation.

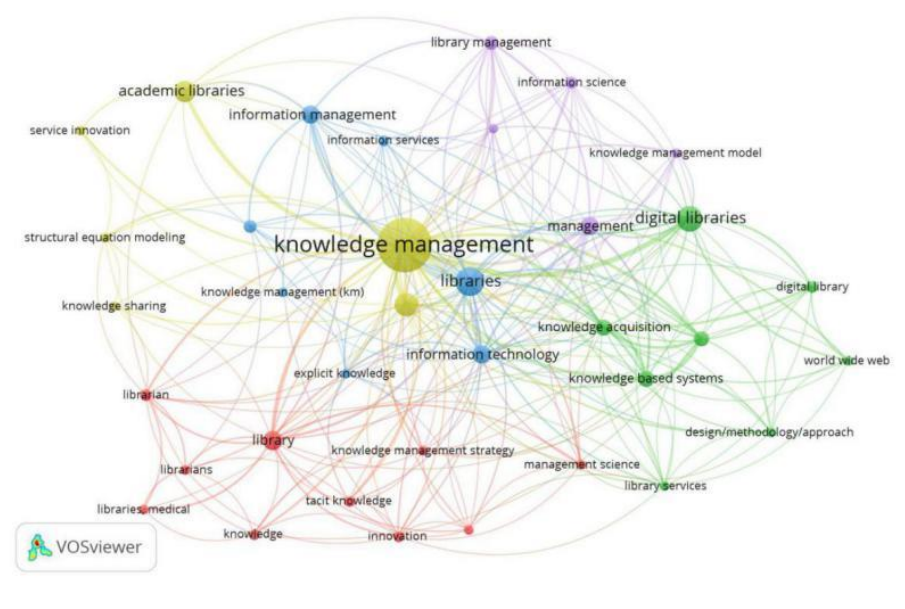

Gambar 3. Network visualization

Analisis metadata menggunakan VosViewer juga menghasilkan overlay visualization. Pada Gambar 4, dengan visualiasi overlay menunjukkan bahwa warna sebuah node menggambarkan peta kata kunci topik penelitian sedangkan warna node menunjukkan tahun terbit publikasi penelitian yang memuat kata kunci tersebut. Semakin gelap warnaya pada node menunjukkan bahwa topik penelitian tersebut sudah lama dilakukan. Dari visualiasi tersebut bahwa information services dilakukan pada tahun 2006, explicit knowledge pada tahun 2007, digital libraries dan medical library dilakukan pada tahun 2008. Knowledge acqusition dilakukan pada tahun 2009, management science, knowledge base system, information management, dan information technology dilakukan pada tahun 2010. Knowledge management strategy, library, tacit knowledge, disign/methodology, digital library, word wide web, knowledge management tool, dan library management dilakukan pada tahun 2011. Knowledge management system, knowledge management, library and information science dialakukan pada tahun 2012. Academic libraries, knowledge sharing, knowledge management model, knowledge mangement, librarian, research development management, dan information science dilakukan pada tahun 2013. Innovation, library services, university libraries dilakukan pada tahun 2014. Librarians (2015), service innovation (2016), dan knowledge (2018). 


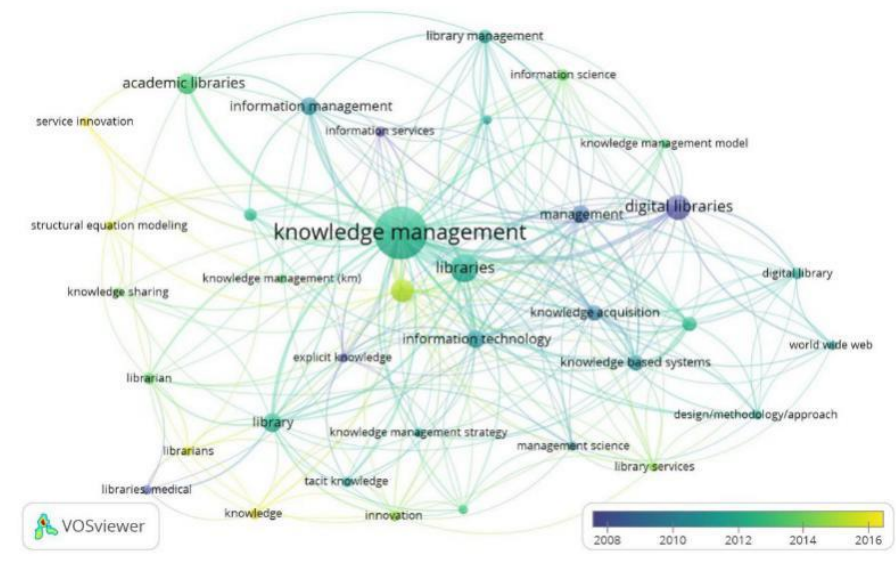

Gambar 4. Overlay visualization

Berdasarkan density visualization seperti pada Gambar 5 berikut menunjukkan bahwa topik penelitian peran perpustakaan dalam mendukung manajemen pengetahuan yang paling banyak diteliti adalah knowledge management, knowledge sharing, libraries, digital libraries, academic libraries, information mangement, information technology. Hal tersebut sesuai pendapat Sahoo et al (2017) yang melakukan kajian manajemen pengetahuan pada jurnal elektronik dengan metode bibliometrik. Hasil penelitian menunjukkan bahwa kata kunci yang sering muncul adalah knowledge management, knowledge sharing, dan knowledge transfer.

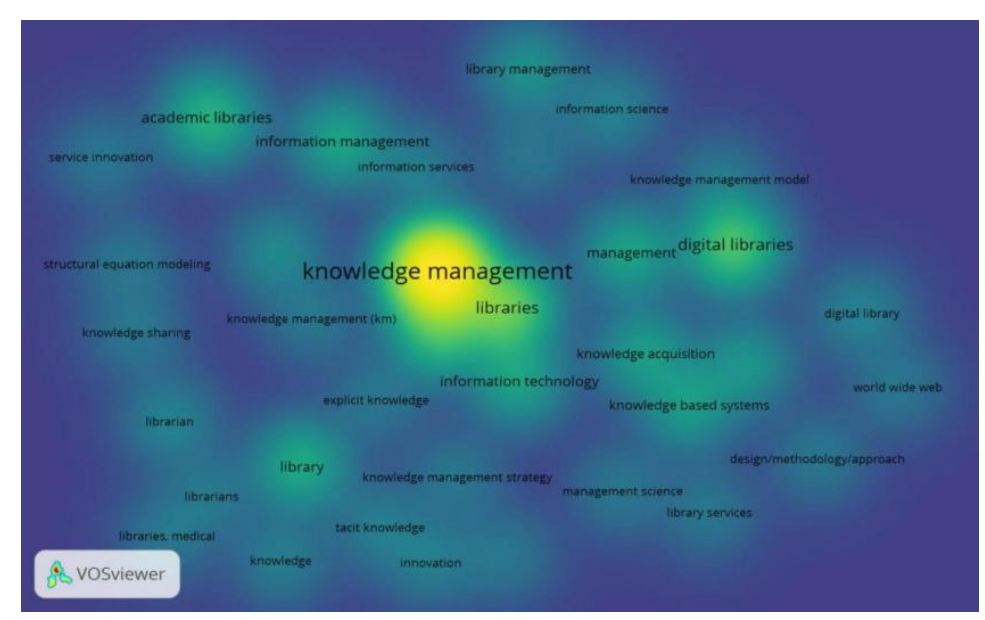

Gambar 5. Density visualization

\section{KESIMPULAN}

Analisis publikasi peran perpustakaan dalam mendukung manajemen pengetahuan yang dilakukan menggunakan sofware VosViewer dapat melihat topik topik yang sudah banyak dilakukan penenelitian maupun belum dilakukan. Dengan diketahuinya topik yang belum banyak dilakukan diharapakan dapat membatu peneliti untuk melakukan. Sedangkan bagi pengambil kebijakan analisis publikasi dengan menggunakan VosViewer dapat digunakan untuk melakukan evaluasi penelitian yang telah dilakukan.

Dari hasil dan pembahasan dapat disimpulkan bahawa publikasi penelitian tentang peran perpustakaan dalam mendukung manajemen pengetahuan terbanyak dilakukan pada tahun 2013 dan tahun 2016. Library Management merupakan sumber publikasi terbanyak dengan jumlah publikasi sebanyak 11 dokumen dengan jumlah sitasi sebanyak 185. Jenis literatur penelitian peran perpustakan dalam mendukung manajemen pengetahuan yang terbanyak 
dalam bentuk artikel. Pemetaan menngunakan sofware VosViewer menunjukan bahwa publikasi penelitian peran perpustakaan dalam mendukung manajemen pengetahuan dibagi dalam empat kluster. Topik penelitian yang paling banyak dilakukan adalah knowledge management system, knowledge management, library and information science, academic libraries, knowledge sharing, knowledge management model, librarian, research development management, information science, Innovation, library services, dan university libraries.

\section{DAFTAR PUSTAKA}

Adelia, N. (2020). Manajemen pengetahuan dalam perpektif perpustakaan. Shaut Al-Maktabah: Jurnal Perpustakaan, Arsip dan Dokumentasi, 12(1), 33-47

Alajmi, B., \& Alhaji, T. (2018). Mapping the Field of Knowledge Management: Bibliometric and Content Analysis of Journal of Information \& Knowledge Management for the Period from 2002-2016. Journal of Information \& Knowledge Management, 17(3), 1-16

Anjas Pratama, Yoga. (2018). Penerapan Knowledge Management di SMK Dipenegoro Depok. AlIdarah: Jurnal Kependidikan Islam, 8(2), 294-306

Daland, H. (2016). Managing Knowledge in Academic Libraries Are we? Should we? Liber Quarterly, 26 (1), 28-41

Haryanto. (2018). Knowledge management di Perpustakaan Perguruan Tinggi. Pustakaloka, 10(1), 40-49

Husna, N., \& Nelisa, M. (2019). Upaya penerapan manjemen pengetahuan di Perpustakaan STIKes Alifah Padang. Jurnal Ilmu Informasi Perpustakaan dan Kearsipan, 8(1), 263-268

Koç, T., Kurt, K., \& Akbiyık, A., (2019). A Brief Summary of Knowledge Management Domain: 10Year History of the Journal of Knowledge Management. Procedia Computer Science, Vol. 158 pp. 891-898.

Pinfield, S., Cox, A. M., Smith, J. (2014). Research data management and libraries: Relationships, activities, drivers and influences. PLoS ONE. 9(12),e114734

Rahayu, N. (2026). Peranan Pustakawan dalam Mendukung Knowledge Manajemen Repository Kementerian Kelautan dan Perikanan. Jurnal Pari. 2(1) 2016: 43-51

Wulandari, R. E., \& Risa, N. (2020). Model Knowledge Management di Perpustakaan Universitas Padjadjaran. Lentera Pustaka: Jurnal Kajian Ilmu Perpustakaan, Informasi dan Kearsipan, 6 (1), 23-36

Sahoo, J., Meher, G., \& Mohanty, B. (2017). Electronic Journal of Knowledge Management: A Bibliometric Analysis. Library Philosophy and Practice, 1638. https://digitalcommons.unl.edu/libphilprac/1638. Diakses Tanggal 9 Desember 2020.

Suwarno, W. (2016). Organisasi Informasi Perpustakaan, Pendekatan Teori dan Praktik, Jakarta: Rajawali Press

Van Nunen, K., Jie, L., Reniers, G., Ponnet, K. (2018). Bibliometric Analysis of Safety Culture Research. Safety Science, 108, 248-258. 